\title{
COMPARATIVE THREE DIMENSIONAL COMPUTED TOMOGRAPHY (CT) SCANS AND ANATOMICAL INVESTIGATION OF RABBIT (Oryctolagus cuniculus) AND CAT (Felis domestica) SKULL
}

\author{
Attia A. A. Moselhy*, Eman A. A. Mahdy \\ Department of Anatomy and Embryology, Faculty of Veterinary Medicine, Zagazig University, \\ Egypt
}

${ }^{*}$ Corresponding author, E-mail: atiaanatomy@gmail.com

\begin{abstract}
This study was conducted to elucidate the comparative anatomical features of the skull of rabbits and cats using CT scans. Adult healthy New Zealand rabbits and Domestic Baladi cats of both sexes, were prepared for X-ray and CT scan of the heads at different positions. The heads were also processed for bone preparation and were photographed at various views. Some measurements were taken to exhibit the main differences between the two animal species. There was a cranial pharyngeal canal in the basisphenoid bone of rabbit, which was absent in cat. The retroarticular process situated caudal to the mandibular fossa in cat and absent in rabbit. The carotid foramen was large and situated only in rabbit ventromedial to the bulla tympanica. The supraorbital process of rabbit extended anteriorly and posteriorly forming rostral and caudal supraorbital fissures. The orbit was located laterally in rabbit rostrally in cat. The facial surface of the maxilla was perforated by several formina in rabbit. A large retroalveolar foramen was found only in the mandible of rabbit. The condyloid process of the mandible was large and present longitudinally in rabbit and transversally in cat. Also, the hyoid bones and the paranasal sinuses were compared at both animals. The hyoid bone located in the mandibular space in rabbit and caudal to this space in cat. The lingual process of the hyoid bone was absent in cat. The middle and great cornuae of the hyoid bone were absent in rabbit. The paranasal sinuses of rabbit were maxillary and ethmoidal sinuses. While in cat, there were frontal, sphenoidal and maxillary sinuses. The combination between the traditional gross morphology of the skulls, X-ray and scan aimed to clarify and confirm all the points of comparison between the two animal species used, which was not achieved by using only one method of them.
\end{abstract}

Key words: rabbit; cat; skull; computed tomography; anatomy

\section{Introduction}

The skull is a highly constructed and integrated part of the axial skeleton. All breeds of domestic rabbits descend from European rabbit (Oryctolagus cuniculus), which is a member of the family Leporidae (rabbits and hares) (1).
The skull is divided into two primary units, neurocranium and basicranium. The brain case provides protection for the brain and opening for cranial nerve connections, the bone of the face provide a location and protection for the organs of special senses. 
The domestic cat (Felis catus), a common buddy animal, is only one of the species in the family Felidae (2). The rabbit is utilized for numerous purposes, including biomedical research, meat and fur production. Rabbits and cats are often used as human substitutes in olfaction and inhalation tests, both of which require the knowledge of their anatomy $(3,4)$.

There are many papers about the morphometric features of the head of cat and rabbit and the gross anatomical studies were required. (5, $6)$.The cat as carnivorous and the rabbit which is herbivores animal, they show certain anatomical peculiarities specially their skeleton. The cat has large brain case and anterior located orbit and the rabbit skull long, narrow and laterally situated orbit.

The current study was conducted to elucidate the comparative anatomical features of the skull of a rabbit and cat as educational tools in veterinary studies.

\section{Materials and methods}

\section{Animals}

The handling of animals in this study was followed the guidelines of the Institutional Animal Care and the Research Ethics Committee of the Zagazig University, with an ethical approval number of (ZU-IACUC/2/F /92/2018).

Adult healthy of each New Zealand rabbits and domestic cats $(\mathrm{n}=10$ for each) of both sexes weighed about 2-4 kg, were used. Rabbits were obtained from a laboratory farm in Faculty of Agriculture, Zagazig University. The age of rabbit was 10 months and cat was 13 months. The cats were purchased from a pet animal's clinic in Zagazig city, Sharkia Governorate, Egypt. Rabbits were injected through the ear vein with Xylazine $(3 \mathrm{mg} / \mathrm{kg})$ followed by injection of Ketamine (3 mg/kg) (7). The dose in cats was $1 \mathrm{mg} / \mathrm{kg}$ of xylazine followed by 5 $\mathrm{mg} / \mathrm{kg}$ of I.M ketamine for sedation and anesthesia (7).

\section{Radiography}

For radiography, the animal heads were photographed in dorsal and lateral position using Mobile Fischer X-ray machine H.G. Fischer, inc. Franklin Park, Illinois, USA, in Department of Surgery, Faculty of Veterinary Medicine, Zagazig University.

\section{Computed tomography}

For (CT), both species were used, at ALBayan Center of radiology and CT in Belbes, Sharkia Governorate, Egypt. CT images were taken without contrast medium using multislices CT system, which was capable of acquiring up to 32 slices per second with fast wholebody scan time of 0.5 seconds, $50 \mathrm{~kW}$ X-Ray Generator, Multiple $\mathrm{kV}$ and $\mathrm{mA}$ techniques and 5.0 MHU X-Ray Tube. TOSHIBA 600HQ (third generation) Japan (8).

\section{Anatomical dissection of heads}

The heads of both species were carefully separated and cleaned from all attached tissues. Also, the intact hyoid bones were carefully dissected. The skulls were prepared following the method of (9). The measurements were taken with a caliper to demonstrate the main differences between the two animal species. The obtained skulls were photographed using a Sony digital camera, Dsc W810 20.1 MP. The weight of animals obtained by using a digital scale. The nomenclatures were taken as a basis for the denomination on the skulls (10). The cranial and facial portions of the skull were described the most characteristic points of differences of both animals. Also, the hyoid bones and the paranasal sinuses were compared at both animals.

\section{Statistical analysis}

All statistical procedures were performed using the SAS statistical system Package V9.2 (SAS, 2009) (11). Differences between means due to different anatomical parameters were tested by student's t-test. Data were reported as mean \pm SEM, and the differences were considered significant at $\mathrm{P} \leq 0.05$

\section{Results}

he apparent point of comparison between two species skull in the current study that, rabbit skull as a whole was long, narrow and compressed. But, that of a cat was short, broad and heavy in weight table 1 . 
The skull is composed of two main portions; cranial and facial.

\section{I- Bones of the cranium}

\section{The occipital bone}

The occipital bone (Fig.1 A, B, C and D) was subdivided into three parts; supra-occipital, lateral part and basioccipital. In rabbit, the occipital bone, shared in the formation of the roof of the cranial cavity and the supra-occipital part was fenestrated and depressed dorsally. The external sagittal crest was sharper, higher and longer in cat than in rabbit. The nuchal crest of rabbit was low, curved and located caudolaterally. However, in a cat, the latter crest was sharp and long. The external occipital protuberance appeared as a sharp elevated ridge in the rabbit and reached to the foramen magnum. While in cat, it was small and separated from the foramen magnum by the external occipital crest. The occipital condyles in a cat were larger and broader than that of the rabbit. The jugular processes were longer in rabbit and closely attached to bulla tympanica in cat. The hypoglossal foramen was double in rabbit and single in cat. The foramen magnum is diamond in shape and notched dorsally in rabbit and rounded in cat. The basilar part of rabbit was longer, wider and increased in thickness rostrally, although in the cat, it had the same width along its whole length.

\section{The interparietal bone}

The interparietal bone was larger and longer in cat than in rabbit (Fig.1A and B). There was an intracranial extension of the interparietal bone termed osseous tentorium cerebeli, which was very large in cat and small in rabbit.

\section{The sphenoid bone}

The basisphenoid in rabbit was wedge shaped and directed rostodorsally with its narrow rostral part was lodged between the ptergyoid bones. In cat, the bone was directed rostrally and quadrate in shape (Figs.1E and F and 2A, $\mathrm{B}$, and $\mathrm{C}$ ). The basisphenoid bone was grooved dorsally in rabbit at its middle; there was a cranial pharyngeal canal which was absent in cat. The wing of the sphenoid bone in cat contained four foramina; rotundum, orbital, optic and ethmoidal foramen. In rabbit, the optic foramen was sited.

\section{The presphenoid}

The presphenoid bone (Fig. $1 \mathrm{E}$ and $\mathrm{F}$ ) in a cat was large, wedge shape separated from the pterygoid bone by the openings of the pterygoid canal. While in rabbit, this bone was located anterior to basisphenoid and anterio- ventral to the optic foramen.

\section{The temporal bone}

The temporal bone (Figs. 1 A, B, E and F, 2 $\mathrm{C}$ and $3 \mathrm{~A}$ and $\mathrm{B}$ ) composed of two parts; Pars petrosa and Pars squamosa. In rabbit, the temporal fossa was small, short, shallow (nearly flat) and it participated in the formation of the posterior part of the orbit. In cat, the fossa was longer, larger and deeper (concave) and located caudal to the orbit. The mandibular fossa articulated with the mandible forming temporomandibular joint. It was located more dorsally in rabbit than in cat (Figs. 2C and 3C and D). The retroarticular process situated caudal to the mandibular fossa in cat and absent in rabbit. The bulla tympanica of rabbit was smaller than in cat and its shape was seashell like but resembling an egg in cat. The external acoustic process was located at high level in rabbit and absent in cat. The external acoustic meatus positioned dorsal to the level of bulla tympanica in rabbit, and it placed rostodorsal to bulla tympanica in cat. The jugular and lacerum anterior foramina were larger in cat than that of rabbit. The carotid foramen was large and situated only in rabbit ventromedial to bulla tympanica (Fig. 1F). The internal acoustic meatus was larger and deeper in rabbit than in cat.

\section{The parietal bone}

The parietal bones participated in the formation of the roof of the cranial cavity in rabbit. But in cat, they were large and shared in the lateral boundary in addition to the roof of the cranial cavity (Fig. 1A and B). 


\section{The frontal bone}

The main parts of the frontal bone were Squama, nasalis and Pars orbitalis. In rabbit, the frontal bone (Figs. 1A, B, 3A, B, C and D and $3 \mathrm{~A}, \mathrm{~B}, \mathrm{E}$ and $\mathrm{F}$ ) was large, narrow, depressed dorsally and tapered anteriorly, forming inverted V-shape between the nasal bones. In cat, it was broad, short and lodged rostrally between the nasal bones and maxilla. The supraorbital process of rabbit was large, prominent. It extended anteriorly and posteriorly forming rostral and caudal supraorbital processes. It constituted the dorsal margin of the orbit. In cat, the supraorbital process was one part, long and it formed the caudal half of the orbital boundary.

\section{The orbit}

The orbit of rabbit was located laterally, slightly oval in shape and it contained one large optic foramen in the interorbital septum (Fig. $3 \mathrm{~A}$ and $\mathrm{C}$ ). The ethmoidal foramen was present just craniodorsal to the latter foramen. The orbit of cat was situated rostrally, rounded in shape and incomplete caudally, but closed by the orbital ligament (Figs. 3B and D and $3 \mathrm{G}$ and $\mathrm{H}$ ).

\section{The ethmoid bone}

The ethmoid bone (Fig. 4 A and B) was consisted of cribriform plate and perpendicular plate in both species. The olfactory fossa of the cribriform plate was deep and small in rabbit but, long dorsovental and shallow in cat. The perpendicular plate in cat was longer, larger and situated in the caudal two third of the short nasal cavity, it was lodged in the sulcus vomeris ventrally. In rabbit, the forementioned plate was small, it did not reach to the level of vomer bone and it was restricted to the most caudal part of the long nasal cavity. So, the bony nasal septum was longer in cat than in rabbit which it was mostly cartilaginous.

\section{II- Bones of the face}

\section{The lacrimal bone}

The lacrimal bones (Figs. $1 \mathrm{~B}$ and $3 \mathrm{~A}$ and B) can be seen from lateral view of the skull and formed the rostromedial part of the orbit. In cat, it was smaller than that of rabbit. In both species, the bone had an opening for the lacrimal canal, which it located between this bone and the maxilla in rabbit.

\section{The nasal bone}

The nasal bones (Figs. $1 \mathrm{~A}$ and B and 3) were larger and longer in rabbit than that of cat. In rabbit, they had the same width along its whole length with notched rostral end. The nasal bones of cat were short, broad rostrally and narrow caudally with the rostral end was curved $\mathrm{C}$ -shaped. In both animals, the caudal end was fitted between the frontal bones. The nasal bone of rabbit was separated from the maxilla by the nasal process of the premaxilla. But in cat, the caudal two third of the bone was related to the maxilla and only the rostral third correlated to the nasal process of the premaxilla. The nasal surface of the nasal bone had a dorsal turbinate crest for attachment of dorsal turbinate bone. In rabbit, the latter crest was long and present in the middle of this surface of the bone, while in cat, the crest was short and ventrally situated.

\section{The premaxilla}

The premaxilla (Figs. $1 E$ and $F, 2, A, B, C$, and $\mathrm{D} 3$ and $4 \mathrm{~A}$ and $\mathrm{B}$ ) of rabbit was large, long and it constituted the rostral part of the lateral wall of the nasal cavity. The premaxilla of cat was short, small and it represented the lateral and ventral boundary of the rostral osseus nasal aperture. In rabbit, the body of the premaxilla had two pairs of upper incisors teeth, the interdental space was very long and the interincisive canal was absent. In cat, it had three pairs of upper incisors teeth and the interdental space was very short or absent. The nasal process of premaxilla of rabbit was long, narrow and it extended caudodorsally until it reached to the frontal bone and making deep nasoincisive notch. While in cat, it was short and extended slightly between the nasal bone and maxilla, forming a shallow nasoincisive notch. In rabbit, the palatine process of premaxilla was long, extended caudally and formed the rostral part of the basis of the hard palate. It united with its followed and surrounded its lateral and caudal sides by long palatine fissures. Meanwhile, the palatine process of premaxilla of cat was very 
short, joined the other side and the palatine fissures were small and short. The premaxilla formed most the basis of the hard palate in rabbit while in cat it formed only one quarter.

\section{The maxilla}

The maxilla consisted of body and two processes; zygomatic and palatine. The body of the maxilla (Figs. 1E and F, 2 and 3) formed the lateral wall of the nasal cavity. In rabbit, the facial surface of the bone was perforated by several formina and had a facial tuberosity laterally and alveolar bulla appeared from the rostroventral part of the orbit. Three foramina were present medial to the maxillary tuberosity; maxillary, sphenopalatine and posterior palatine foramen. In cat, there were no facial nor maxillary tuberosities. The infraorbital canal was very short in cat and extended dorsoventrally but, it was long and extended in a craniocaudal manner in rabbit. The facial tuberosity prolonged caudally into zygomatic process and reached to the malar bone. The dorsal border of the maxilla related to the nasal process of premaxilla in rabbit and to the nasal bone in cat. The alveolar border of the maxilla carried two premolar, three molar and a small molar tooth present caudally in rabbit. However, in cat, this border had one pair of canine, three pairs of premolar and one molar teeth. The zygomatic process of maxilla directed upward and backward joined the zygomatic bone. The palatine process of maxilla of cat was larger and broader than that of rabbit. This process of rabbit had a pointed rostral end and it formed the caudal boundary of the palatine fissure. In both species, the nasal surface of the maxilla contained maxillary sinus and ventral turbinate crest. In rabbit, the bony lacrimal canal was long and crossed the whole length of latter surface of the maxilla at its middle part. In cat, the bony lacrimal canal was very short and situated ventrally in the caudal part of the nasal surface of the maxilla.

\section{The turbinate bones}

In rabbit, the ethmoturbinate bone was narrower than cat and it was restricted to the caudal half of the nasal cavity. In both species, it was situated below the dorsal turbinate bone and caudal to the ventral turbinate bone. The dorsal turbinate bone in rabbit was long, narrow and it had a middle bulged part while in cat; it was broad, short and placed dorsal to the ethmoturbinate. The ventral turbinate bone in rabbit was larger than cat and situated rostral to the ethmoturbinate and ventral to the dorsal turbinate bone. While in cat, it was very small and positioned ventral to the ethmoturbinate (Fig. 4A and B).

\section{The cavities of the skull}

The cranial cavity in general was larger in cat than rabbit. The rostral end of this cavity in cat was wide and separated from the frontal bone by the frontal sinus. But in rabbit, it was narrow and located in higher level just below the frontal bone due to the absence of the frontal sinus. The nasal cavity was longer in rabbit than cat. In cat, it was about half the length of the cavity in rabbit (Fig. 4 A and B).

\section{The palatine bone}

It consisted of Lamina horizontalis and perpendicularis (Fig. 1E and F). In rabbit, the horizontal part of the palatine bone represented eighth the bony part of the hard palate. In cat, it symbolized half of the latter. The bone contained the rostral palatine foramen at the level of the $3^{\text {rd }}$ upper premolar tooth in rabbit and located between the level of the $2^{\text {nd }}$ and $3^{\text {rd }}$ upper premolar teeth in cat. The perpendicular part of the palatine bone was narrow in rabbit and broad in cat. In both species the perpendicular part formed the lateral boundary of the posterior nares.

\section{The pterygoid bone}

In rabbit, the pterygoid bone (Figs. $1 \mathrm{E}$ and $\mathrm{F}$, $2 \mathrm{~A}$ and $2 \mathrm{C}$ ) was larger than that of cat. It was very thin, transparent bone. Also, it had two pterygoid processes, each of them enclosed a triangular cavity termed pterygoid fossa. At the base of the latter fossa, there was alar foramen. In cat, the pterygoid bone was small connected rostrally with the perpendicular plate of the palatine bone by pterygopalatine suture. Its ventral border carried long pointed hamulus pterygoideus. There were two foramina between the 
pterygoid bone and the body of the sphenoid bone (foramina of pterygoid canal).

\section{The zygomatic bone}

In rabbit, the zygomatic bone (Figs. $1 \mathrm{~A}$ and $\mathrm{B}, 2 \mathrm{~B}, \mathrm{C}$ and $\mathrm{D}$ and $3 \mathrm{~A}$ and $\mathrm{B}$ ) was smaller, shorter and narrower than that of a cat. It formed a small ventral part of the rabbit orbit and all the ventral boundary of the cat orbit. The zygomatic process of this bone in rabbit extended more caudally than the level of the same process of the temporal bone. In cat, the caudal end of this bone was bifid into dorsal frontal and ventral zygomatic processes. The zygomatic process was longer, narrower and joined the zygomatic process of the temporal bone.

\section{The vomer bone}

The vomer bone (Figs. 1E, $3 \mathrm{G}$ and $\mathrm{H}$ and $4 \mathrm{~A}$ and B) was short, straight and located more rostrally in cat. It was long and curved rostroventrally in rabbit. The bone was broader in rabbit than cat while, the sulcus vomeris was larger in cat. The vomer bone ended at the level of the rostral end of the nasal bone in cat. However, in rabbit it was parallel to the caudal two third of the nasal bone. In rabbit, the bone can be seen from the large palatine fissure. While in cat, it is not seen from the short palatine fissure. In both species, the vomer bone not divided the posterior nares.

\section{The mandible}

The mandible (Figs. $4 \mathrm{C}$ and D and 5A) composed of body and two rami. In rabbit, the body was longer, narrower and represented by two parts; incisive and molar. While in cat, the body was short, broad and thick. The lower jaw in rabbit carried one pair of lower incisor, two premolar and three molar teeth. But in cat, there were two pair of incisor, one pair of canine, two premolar and one molar tooth. The rabbit had no canine teeth so, there was long inter-dental space (diastema). The latter was very short or nearly absent in cat. In rabbit, Symphysis mandibulae was long and clear ventrally than dorsally. However, in cat it was short and well distinct dorsally and ventrally. The lateral surface of the body of the mandible of rabbit was perforated by several formina resemble that of the maxilla. The mental foramen of rabbit was only one and present laterally on the body, away from the incisor teeth, just in front the first premolar tooth. In cat, the latter foramen was two in number; rostral and caudal. These foramina located more forward than in the rabbit. A large retroalveolar foramen was found only in rabbit, just caudal to the last molar tooth. The ramus of the mandible in rabbit was thin, transparent plate of bone its lateral surface had sallow massetric fossa and the medial one contained deep pterygiod fossa and fovea pterygoidea. At the cranial margin of the latter fossa, the mandibular foramen was located. The ramus of the mandible of cat was thick and compact. It had deep massetric fossa and the mandibular foramen present caudally than in the rabbit. The angle of the mandible and the vascular notch were clear in rabbit. The condyloid process was large and present longitudinally in rabbit and transverslly in cat. The mandibular notch in rabbit was shallower than in cat and it is located rostral to the condyloid process. In rabbit, the coronoid process was thin and it bent medially above a deep groove on the rostral border of the ramus. While in cat, the coronoid process was thick and elevated dorsally. Distal to the condyloid process, positioned Collum mandibulae in rabbit and angular process in both species. The madibular space was narrow in rabbit and wide in cat.

\section{The hyoid bone}

In rabbit, the hyoid bone (Figs. $2 \mathrm{~A}$ and $\mathrm{C}, 3 \mathrm{D}$ and $5 \mathrm{~B}, \mathrm{C}, \mathrm{D}$ and $\mathrm{E}$ ) located in the mandibular space. While in cat, it situated caudal to the mandibular space. The hyoid bone of rabbit was smaller than that of a cat. It consisted of four parts; body (basihyoideum), small cornua (ceratohyoideum), somewhat long thyrohyoideum and short lingual process. In cat, the bone formed of five parts. The lingual process was absent in cat. In addition to the parts of the bone in rabbit present middle (epihyoideum) and great (stylohyoideum) cornuae. Basihyoideum of rabbit was large and quadrilateral in shape. While in cat, it was narrow and small plate of bone (Fig. 5A, B, C, D and E). There was no articulation between the hyoid bone and the skull of rabbit, but in cat, the great cornua 
had tympanohyoideum which articulate with the mastoid process of the temporal bone (Figs. $3 \mathrm{D}$ and $5 \mathrm{C})$.

\section{Paranasal sinuses:}

The paranasal sinuses of rabbit were two in number; maxillary and ethmoidal sinuses. While in cat, there were three paranasal sinuses; frontal, sphenoidal and maxillary sinuses (Figs. $4 \mathrm{~A}$ and $\mathrm{B}$ and $5 \mathrm{~F}, \mathrm{G}, \mathrm{H}$ and $\mathrm{I}$ ).

Table 1: Anatomical measurements of the skull and mandible between rabbits and cats

\begin{tabular}{|c|c|c|c|}
\hline Anatomical measurements & Rabbits & Cats & P-Values \\
\hline Skull length $(\mathrm{cm})$ & $8.98 \pm 0.18$ & $10.05 \pm 0.13$ & 0.003 \\
\hline Skull width (at the middle of the orbit) & $4.02 \pm 0.11$ & $6.47 \pm 0.12$ & 0.000 \\
\hline Cranium length & $4.27 \pm 0.17$ & $4.52 \pm 0.11$ & 0.281 \\
\hline Nasal cavity length & $4.07 \pm 0.11$ & $3.05 \pm 0.16$ & 0.002 \\
\hline Nasal bone length & $3.97 \pm 0.13$ & $1.20 \pm 0.10$ & 0.000 \\
\hline Orbit Height & $1.47 \pm 0.08$ & $2.07 \pm 0.11$ & 0.005 \\
\hline Breadth & $2.25 \pm 0.11$ & $2.97 \pm 0.10$ & 0.004 \\
\hline Base of the skull (length) & $1.05 \pm 0.11$ & $2.05 \pm 0.13$ & 0.001 \\
\hline \multicolumn{4}{|l|}{ Foramen magnum } \\
\hline Height & $0.40 \pm 0.4$ & $0.50 \pm 0.04$ & 0.157 \\
\hline Breadth & $0.62 \pm 0.03$ & $0.70 \pm 0.01$ & 0.111 \\
\hline \multicolumn{4}{|l|}{ External acoustic meatus } \\
\hline Height & $0.39 \pm 0.13$ & $0.49 \pm 0.16$ & 0.004 \\
\hline Breadth & $0.39 \pm 0.02$ & $0.78 \pm 0.16$ & 0.000 \\
\hline Zygomatic arch length & $4.10 \pm 0.12$ & $5.52 \pm 0.28$ & 0.008 \\
\hline Mandible length & $7.02 \pm 0.16$ & $6.57 \pm 0.13$ & 0.081 \\
\hline Ramus of the mandible height & $4.00 \pm 0.15$ & $3.02 \pm 0.11$ & 0.002 \\
\hline Mandibular space & $3.05 \pm 0.17$ & $4.97 \pm 0.17$ & 0.000 \\
\hline Mandibular symphysis (length) & $2.22 \pm 0.12$ & $1.45 \pm 0.11$ & 0.008 \\
\hline Weight of the skull (without mandible) (gm) & $15.07 \pm 0.11$ & $40.12 \pm 0.41$ & 0.000 \\
\hline Weight of mandible (two rami) (gm) & $8.02 \pm 0.13$ & $10.00 \pm 0.12$ & 0.000 \\
\hline
\end{tabular}



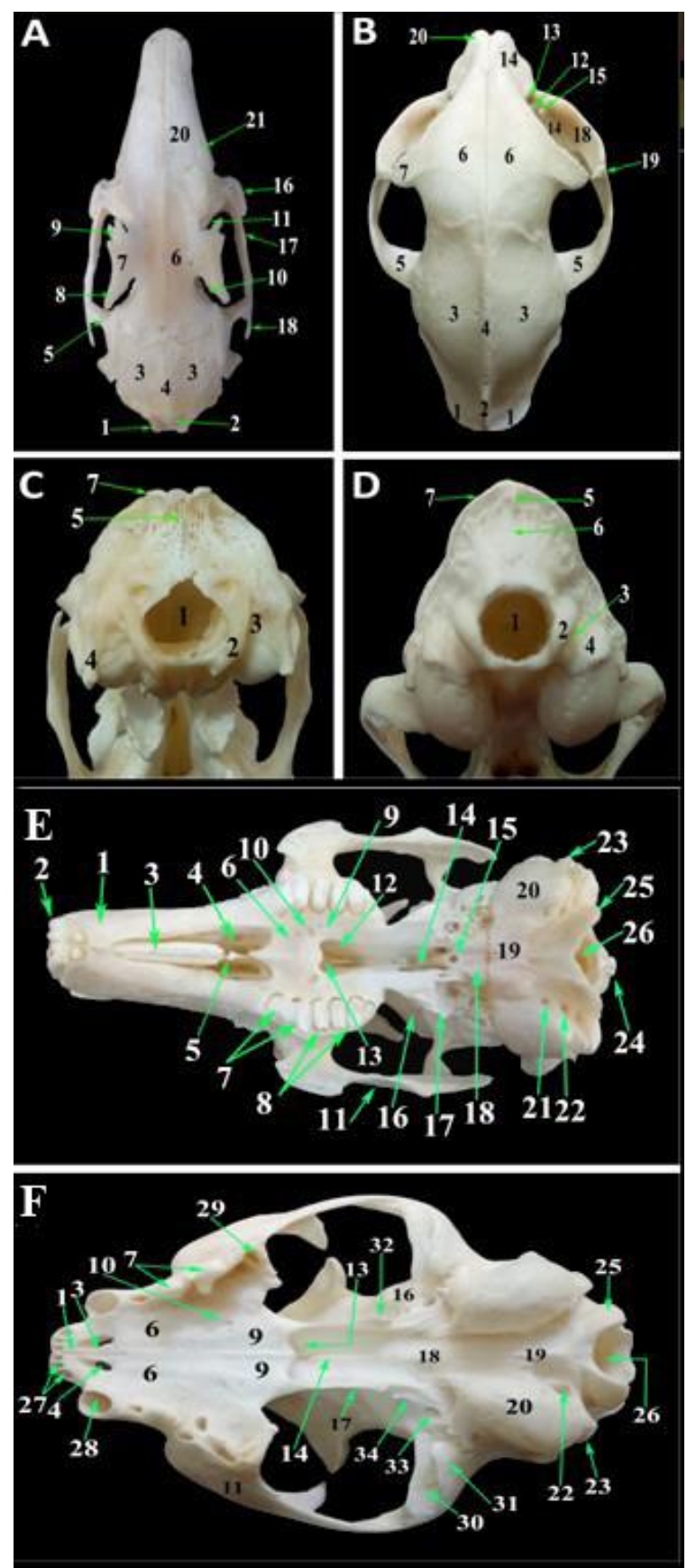

Figure 1: Photomacrographs of the dorsal aspect of the rabbit skull (A) and cat (B): 1- Squama occipitalis 2- Os interparietale 3-Os parietale 4- Crista sagittalis externa 5- Processus zygomaticus os temporal 6- Os frontale 7- Processus supraorbitalis 8- caudal branch of (7) 9- rostral branch of (7) 10- Incisura supraorbitalis caudalis 11- Incisura supraorbitalis rostralis 12- Os lacrimale 13- Foramen lacrimale 14- Maxilla 15- Foramen maxillare 16- Tuber faciale 17- Processus zygomaticus Maxilla 18- Os zygomaticum 19- Processus frontalis os zygomaticum 20- Os nasale 21Processus nasalis os incisivum. Photomacrographs of the caudal aspect of the skull rabbit (C) and cat (D): 1- Foramen magnum 2- Condylus occipitalis 3- Fossa condylaris 4-Processus jugularis 5- Protuberantia occipitalis externa 6Crista occipitalis externa 7- Crista nuchae. Photomacrographs of the ventral aspect of the skull of rabbit (E) and cat (F) 1- Corpus ossis incisivi 2- Dentes incisivi 3- Processus palatinus os incisivum 4- Fissura palatines 5- Vomer 6Processus palatines Maxilla 7- Dentes premolars 8- Dentes molars 9- Lamina horizontalis os palatinum 10-Foramen palatinum majus 11- Os zygomaticum 12- Lamina perpendicularis os palatinum 13- Choanae 14- Os presphenoidale 15- Canalis craniopharyngeus 16- Ala presphenoidale 17- Os pterygoideum 18- Os basisphenoidale 19- Pars basilaris os occipital 20- Bulla tympanica 21- Canalis caroticus 22-Foramen jugulare 23- Processus jugularis 24- Protuberantia occipitalis externa 25- Condylus occipitalis 26- Foramen magnum 27- Alveoli incisivi 28- Alveoli caninus 29- Alveoli molars 30- Fossa mandibulae 31- Processus retroarticularis 32- Hamulus pterygoideus 33- Foramen alare caudalis 34Foramen alare cranialis 

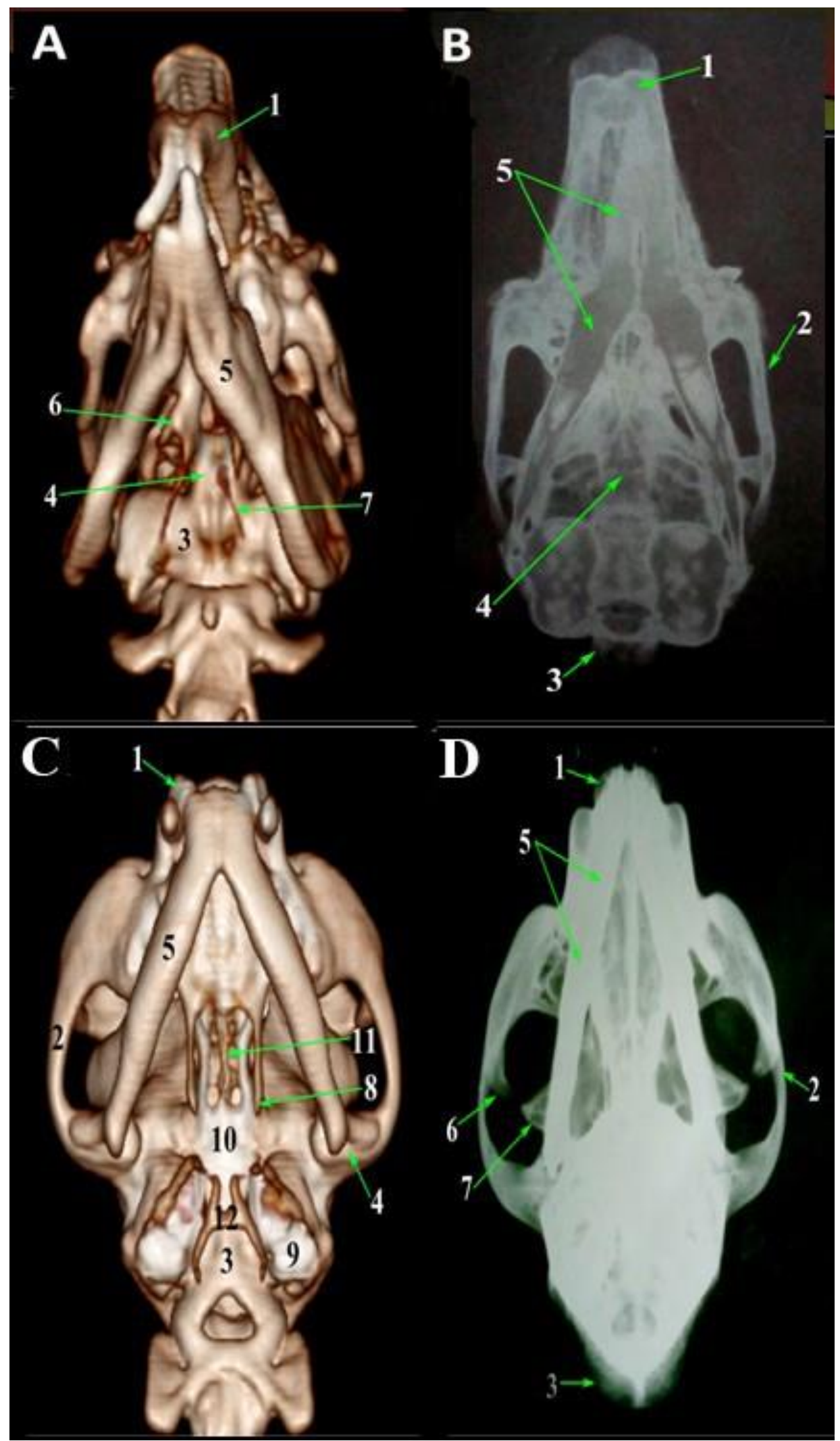

Figure 2: CT scan (A) and X-ray (B) images of the rabbit head (ventral view): 1- Os incisivum 2- Os zygomaticum 3- Os occipitale 4- Os basisphenoidale 5- Mandibula 6- Processus pterygoideus 7- Os hyoideum. CT (C) and X- ray (D) images of the cat head (ventral view): 1- Os incisivum 2- Os zygomaticum 3- Os occipital 4- Articulatio temporomandibularis 5- Mandibula 6- Processus frontalis os zygomaticum 7- Processus zygomaticus os frontale 8- Hamulus pterygoideus 9- Bulla tympanica. 10-Os basisphenoidale 11- Os presphenoidale 12- Os hyoideum 

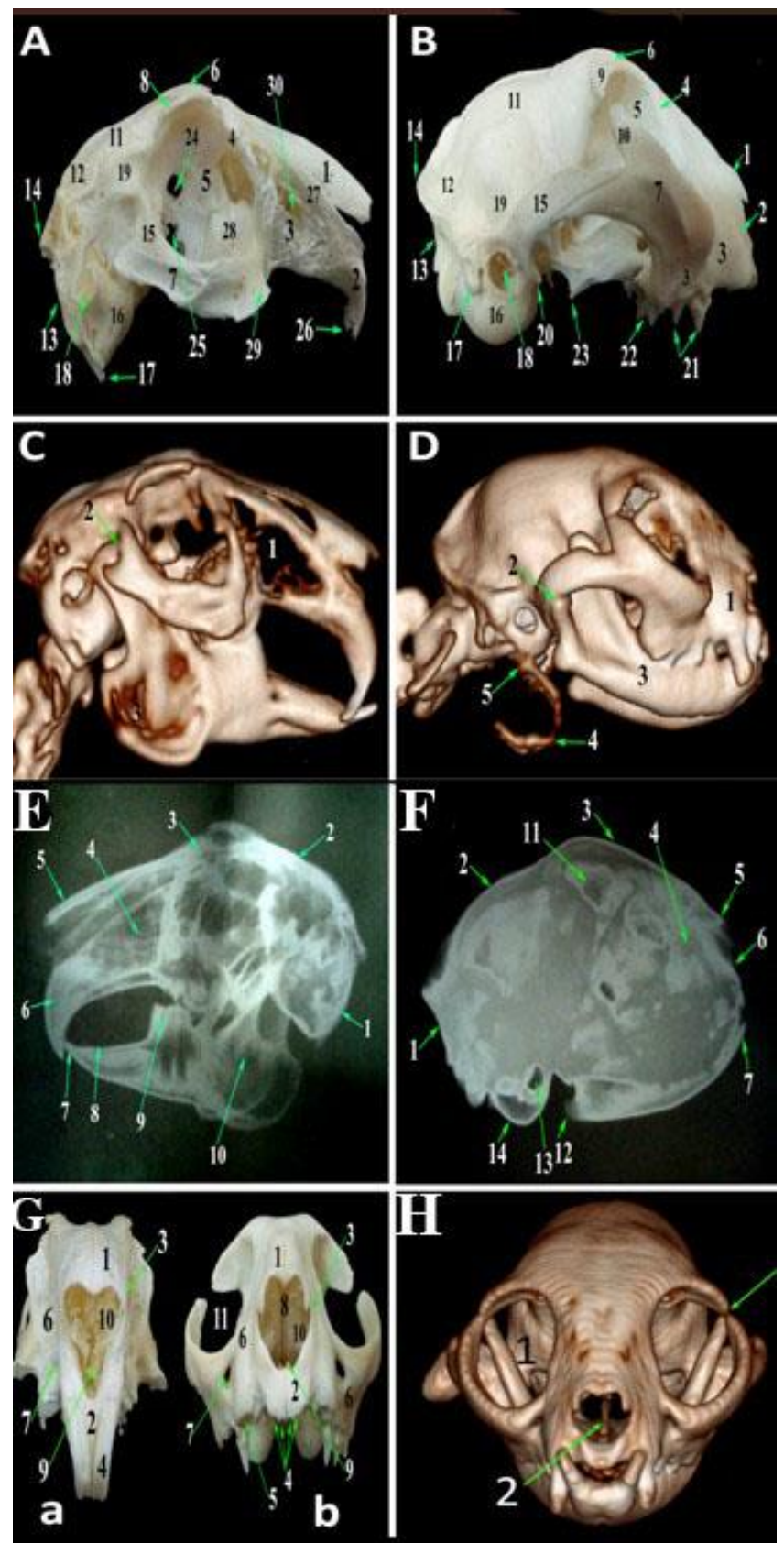

Figure 3: Photomacrographs of the lateral aspect of the rabbit skull (A) and cat (B): 1-Os nasale 2-Os incisivum 3Maxilla 4-Os lacrimale 5-Orbita 6-Os frontale 7-Os zygomaticum 8-Processus supraorbitalis 9- Processus zygomaticus os frontale 10-Processus frontalis os zygomaticum 11-Os parietale 12-Os interparietale 13-Os occipitale 14-Crista nuchae 15-Processus zygomaticus os temporale 16-Bulla tympanica 17-Processus jugularis 18-Meatus acusticus externus 19- Pars squamosa os temporale 20-Processus retroarticularis 21- Dentes premolares 22- Dentes molars 23Hamulus pterygoideus 24- Canalis opticus 25- Fissura orbitalis 26- Dentes incisivi 27- Processus nasalis os incisivum 28- Tuber maxillae29- (Tuber faciale 30- Sinus maxillaries. CT images of the rabbit (C) and cat (D) heads (lateral view) : 1- Maxilla (fenestrated in rabbit) 2- Articulatio temporomandibularis 3- Mandibula (fenestrated in rabbit) 4Os hyoideum 5- Site of attachment of Os hyoideum with the skull. X- ray images of rabbit (E) and cat (F) heads (lateral view) demonstrating: 1- Os occipitale 2- Os parietale 3- Os frontale 4- Maxilla 5- Os nasale 6- Os incisivum 7- Dentes incisivi (Alveoli incisivi) 8- Margo interalveolaris 9- Dentes premolares (Alveoli premolars) 10- Fossa masseterica 11- Sinus frontalis 12- Processus angularis 13- Meatus acusticus externus 14-Bulla tympanica. Photomacrographs of the rostral aspect of the skull of a rabbit (G-a) and cat (G-b) showing: 1- Os nasale 2- Os incisivum 3Processus nasalis os incisivum 4- Dentes incisivi (Alveoli incisivi) 5- Alveoli caninus 6- Maxilla 7- Foramen infraorbitale 8- Lamina perpendicularis os ethmoidale (Septum nasi osseum) 9- Vomer 10- Os conchae nasalis 11- Orbita. $\mathrm{CT}$ image of the cat head $(\mathrm{H})$ (rostral view) demonstrating the orbit (1) which closed with orbital ligament (arrow) and vomer bone (2) 

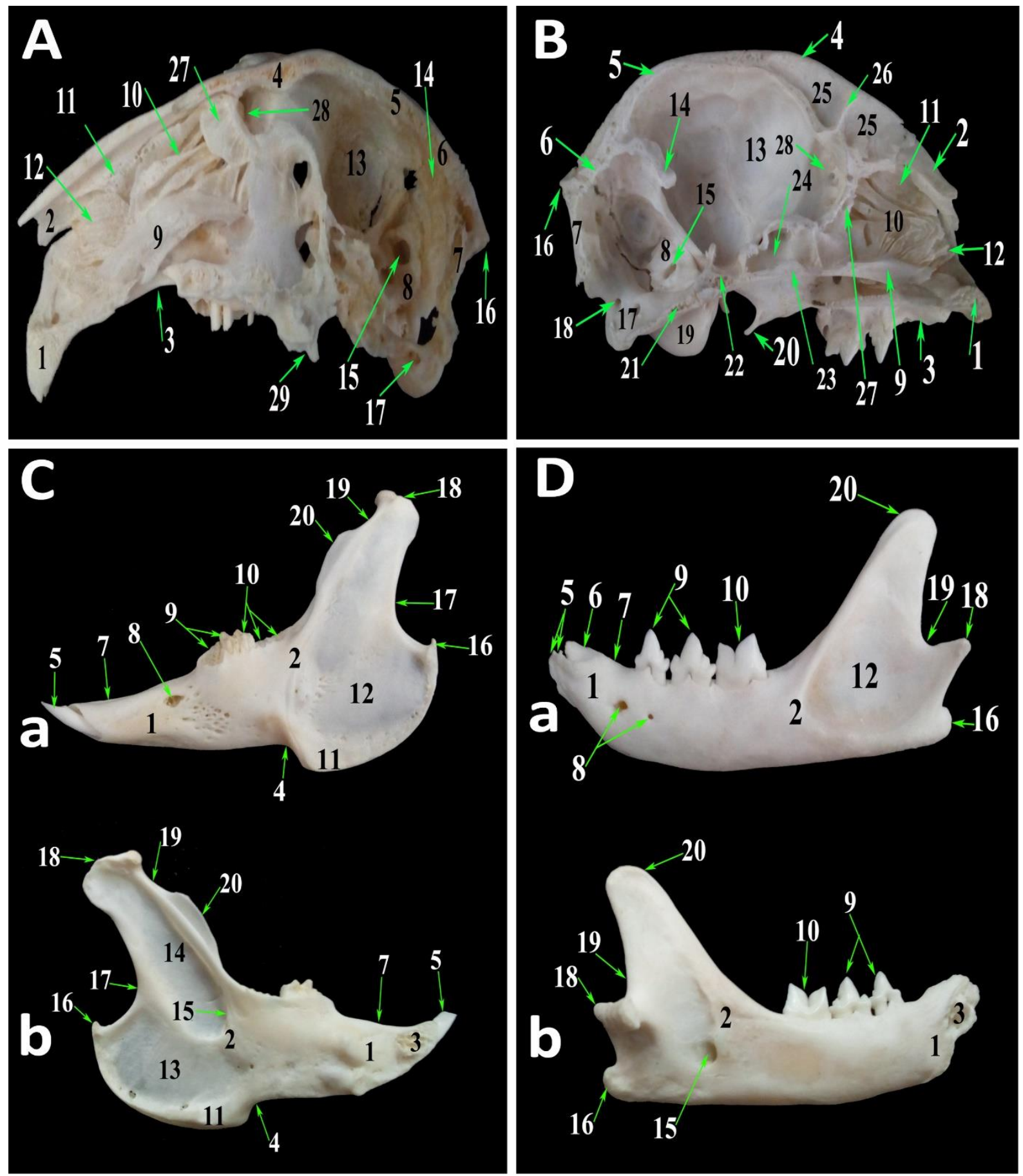

Figure 4: Photomacrographs of the sagittal section of the skull of rabbit (A) and cat (the perpendicular part of the ethmoid bone removed) (B): 1- Os incisivum 2- Os nasale 3- Maxilla 4- Os frontale 5- Os parietale 6- Os interparietale 7- Os occipital 8- Os temporal 9- Vomer 10- Ethmoturbinalia 11- Os conchae nasalis dorsalis 12- Os conchae nasalis ventralis 13- Cvaum crania 14-Tentorium cerebelli osseum 15- Meatus acusticus internus 16- Crista nuchae 17- Processus jugularis 18-Canalis hypoglossi 19- Bulla tympanica 20- Hamulus pterygoideus 21- Pars basilaris os occipital 22- Os basisphenoidale 23- Os presphenoidale 24- Sinus sphenoidalis 25- Sinus frontalis 26- Septa sinuum frontalium 27- Lamina perpendicularis os ethmoidale 28- Lamina cribrosa os ethmoidale 29- Processus pterygoideus. Photomacrographs of the mandible of rabbit (C) and cat (D) lateral (a) and medial (b) surfaces: 1- Corpus mandibulae 2Ramus mandibulae 3- Symphysis mandibulae 4- Incisura vasorum facialium 5- Dentes incisivi 6- Alveoli caninus 7Margo interalveolaris 8- Foramina mentalia 9- Dentes premolares 10- Dentes molars 11- Angulus mandibulae 12Fossa masseterica 13- Fossa pterygoidea 14- Fovea pterygoidea 15- Foramen mandibulae 16- Processus angularis 17Collum mandibulae 18- Processus condylaris 19- Incisura mandibulae 20- Processus coronoideus 

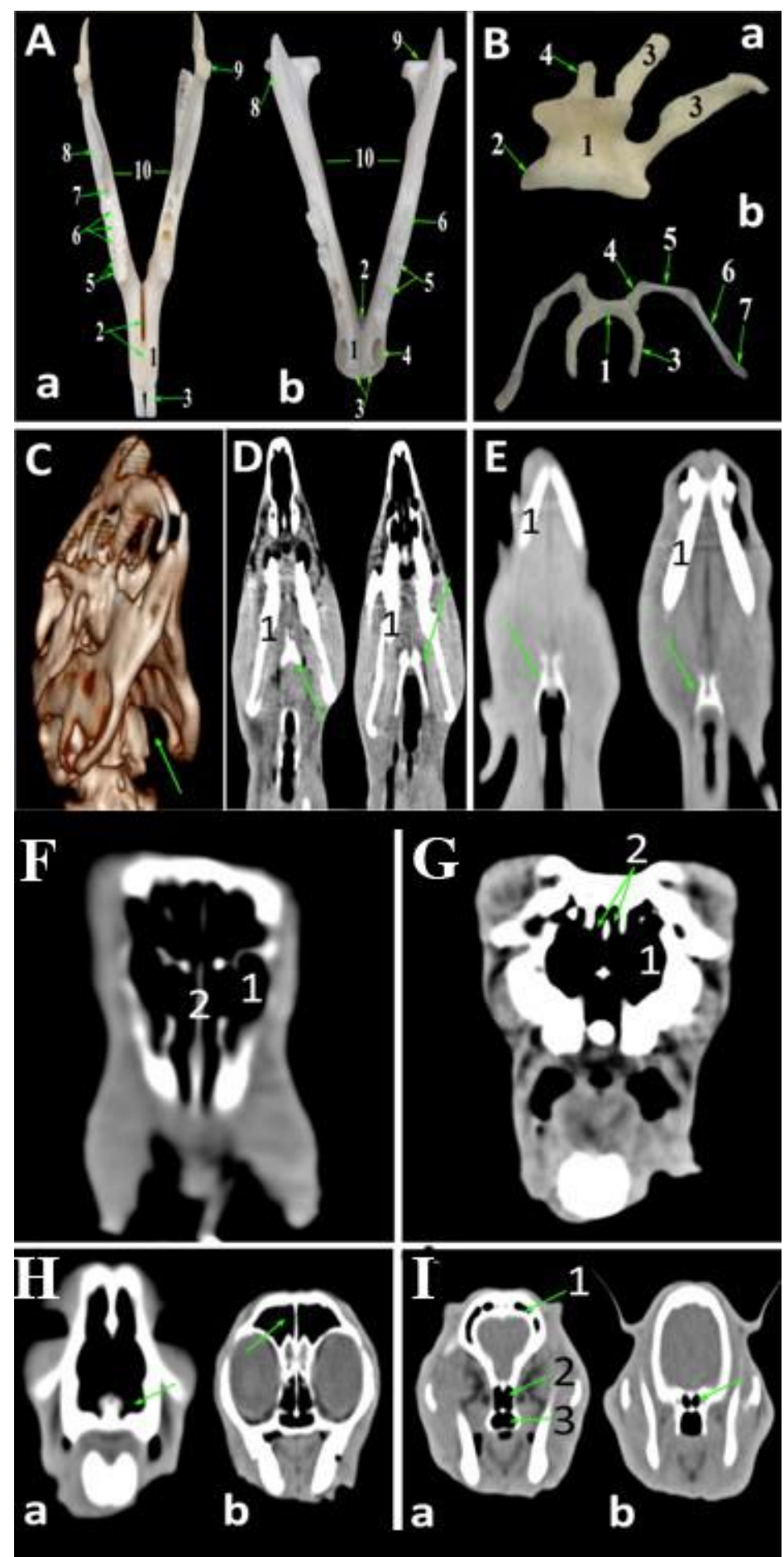

Figure 5: Photomacrographs of the mandible (rostral view) of rabbit (A-a) and cat (A-b) 1- Corpus mandibulae 2Symphysis mandibulae 3- Dentes incisivi 4- Alveoli caninus 5- Dentes premolares 6- Dentes molars 7- Foramen retroalveolaris 8- Processus coronoideus 9- Processus condylaris 10- Mandibular space. Photomacrographs of the hyoid bone of rabbit (B-a) and cat (B-b) 1- Basihyoideum 2- Processua lingualis 3- Thyrohyoideum 4- Ceratohyoideum 5- Epihyoideum 6- Stylohyoideum 7- Tympanohyoideum. CT image of the rabbit head (D) (ventrolateral view) demonstrating the absence of articulation between the hyoid bone and the skull (arrow). CT images of the rabbit (D) and cat (E) heads (ventral view) demonstrating the hyoid bone at different levels (arrows) and Mandibula (1). CT image of the rabbit head (F) sinus maxillaries at anterior level (1) and septum nasi (2). CT image of the rabbit head (G) sinus maxillaries at posterior level (1) and sinus ethmoidales (2). CT images of the cat head (H) sinus maxillaries (a-arrow) and sinus frontalis at anterior level (b-arrow). CT images of the cat head (I) sinus frontalis at posterior level (a-1) which divided by septa sinuum frontalium, Sinus sphenoidalis (a-2), nasopharynx (a-3) and Sinus sphenoidalis at posterior level (b-arrow) which was divided by a median longitudinal partition 


\section{Discussion}

The cranium was much longer than the facial region in leopard cat. The orbit and the cranial cavity were large in the domestic cat, which agreed with the same result in leopard cat (12). The head of Persian cats was characterized by a short face and open orbits $(13,14)$ which was in the same line with the current study. The shape of the skull was differed in the same species as quadrate in domestic rabbits and elongated flat in wild rabbits (15). In agreement with (16), the parietal bones in cat were large and they cover the most of the roof of the cranial cavity.

The features of the occipital bone in rabbit were confirmed by (17). The caudal aspect of the skull of cat was formed by the occipital bone, which it was triangular in shape, this finding correlated with (16) in Jungle cat. The jugular process was short and small and the foramen magnum was rounded in cat, this finding agreed with (18). The paracondylar process was sharper in leopard cat than in domestic cat (12). The supraorbital process of rabbit extended anteriorly and posteriorly forming rostral and caudal parts, which was similar to that observed by $(17,19,20)$. The middle depression of the frontal bone in domestic cat was not observed in Jungle cat (16).

In the present study, the bulla tympanica of the rabbit was smaller than in the cat and its shape was a seashell like but an egg like in the cat. On the other hand $(17,20)$ described the tympanic bulla of the rabbit as a rounded structure. (21) added that the tympanic bulla of dog and cat extended in a lower level than the occipital bone. The mastoid process was short in cat and the jugular processes were longer in rabbit. The external acoustic process in rabbit appeared as a long tube, but in cat it was nearly absent or took the shape of a bony ring that came in accordance with (21) in cat. The bulla tympanica of cat was very large and was lodged caudolaterally which was similar to the leopard cat (12) meanwhile, the external acoustic meatus found dorsally but more rostrally in the present work and at the dorsal border of bulla tympanica in leopard cat.
The zygomatic process of the zygomatic bone in rabbit extended more caudally than the level of the same process of the temporal bone in addition to the absence of the retroarticular process that made a difference in the temperomandibular joint from that of dog and cat that agreed with the results of $(17,19)$. There were two optic canals in cat and single optic foramen in rabbit, similar observation recorded by $(17,19)$. The incisive bones were large, long in the rabbit and characterized by very long nasal process, had two pairs of upper incisor teeth, long interdental space and absence of the interincisive canal and the canine tooth. This observation was characteristic to the skull of the rabbit as an herbivorous animal and simulated the results of $(17,19)$. In rabbit, the palatine processes and fissure of the premaxilla were long, so the former composed most the basis of the hard palate. On the other hand, the palatine processes in cat were very short formed only one quarter of the basis of the hard palate and the palatine fissure was extremely short and small. Similar descriptions were evidenced by (17). In contrast to the current study, (15) in cat demonstrated that, the horizontal part of the palatine bone showed two elevations on either side of the median plane.

The infra-orbital foramen in rabbit was situated at the level of the first premolar tooth, similar result was recorded by $(22,23)$. The facial crest was absent in domestic cat and the infraorbital canal was very short as in dog and cat $(24,25)$ in contrary to the other domestic animal, this crest was clear (18). The basisphenoid bone of rabbit was characterized by the presence of cranial pharyngeal canal, this foundation agreed with (17). This canal had different names in the previous studies, foramen cavernosum (19). In the present study, the mandible of the rabbit was characterized by lack of canine teeth, long diastema and symphysis mandibulae, perforated lateral surface, presence of retroalveolar foramen and peculiar condyloid and coronoid processes. This result was similar to that recorded by $(17,26)$. The lateral surface of the mandibular ramus located had masseric fossa and there were several mental foramina at the rostrolateral aspect of the mandible in, it 
correlated (16). The hyoid bone of rabbit lacked epihyoideum and stylohyoideum as reported by $(17,27$, and 28). So, there was no articulation between the hyoid bone and the skull of rabbit. The latter authors found muscular attachment between the bone and the skull. On the contrary, (27) in rabbit referred to the articulation between the ceratohyoideum and the occipital bone.

The paranasal sinuses of rabbit were maxillary and ethmoidal sinuses, meanwhile, $(29,30)$ stated that maxillary and dorsal conchal sinuses were existed. On the contrary, $(31,32,33)$ recorded only the maxillary paranasal sinus. The ethmoidal sinus of the rabbit in the present work was confirmed by the observations of $(34,35$, 36). The paranasal sinuses of the cat were frontal, sphenoidal and maxillary sinuses, this finding was agreed with that of (36). This study can be applied in a veterinary clinic of cat and rabbit such as regional anesthesia during the treatment of head injury and dental extraction.

\section{Conclusion}

There were great differences between rabbit and cat in the bones forming the cranial cavity, nasal cavity, orbit, hard palate and jaws. Also, numerous variations recorded in the hyoid bone of the two animals; in its position, parts and articulation between this bone and the skull. The paranasal sinuses varied in rabbit than cat; in its number and bones contained them. So, the skull of each animal gave it complete adaptation with the nature of rabbit as herbivores and cat as carnivorous animals.

\section{Conflict of interest}

The authors declare that they have no conflict of interest.

\section{Acknowledgments}

The authors thank Professor Mervat Konsowa, Head of Anatomy and Embryology Department, Faculty of Veterinary Medicine, Zagazig University, Egypt for beneficial comments on the manuscript.

\section{References}

1. Nathan R. Biology of the rabbit. J of the American Association for Lab Anim Sci, 2006; 45: 8-24.

2. Pitakarnnop T, Buddhacha K, Euppayo T, Kriangwanich W, Nganvongpanit K. Feline (Felis catus) skull and pelvic morphology and morphometry: gender-related difference. Anat Histol Embryol. 2017; 46 : 294-303.

3. Norris Reinero CR, Decile KC, Berghaus $\mathrm{RD}$, Williams KJ, Leutenegger CM, Walby Schelegle WF, Hyde DM, Gershwin LJ. An Experimental Model of Allergic Asthma in Cats Sensitized to House Dust Mite or Bermuda Grass Allergen. Int Arch Allergy Immunol. 2004; 135: $117-$ 31 .

4. Xi J, Si XA, Kim J, Zhang Y, Jacob RE, Kabilan S, Corley RA. Anatomical Details of the Rabbit Nasal Passages and Their Implications in Breathing, Air Conditioning, and Olfaction. Anat Rec. 2016; 299: 853-8.

5. Saber AS, Caceci T, Gummow B, Johns K. Morphometric Studies on the Skull of the Australian Domestic Cat (F. catus) and its Clinical Implications for Regional Anesthesia. J. Vet. Anat. 2016; 9 (1) : $1-24$.

6. Gürbüz I, DemiraslanY, Aslan K. Morphometric Analysis of the Skull of New Zealand Rabbit (Oryctolagus cuniculus L.) According to Gender. A RC J Anim and Vet Sci. 2015;1 (1): 27-32.

7. Hall LW, Clarke KW, Trim CM. Veterinary Anaesthesia. 10th ed. WB Saunders. Harcourt Publishers Limited. 2001; $441-66$.

8. Bohler A, Henninger W. Computed tomography of the rabbit head without general anaesthesia.Vet. Med. Austria / Wien. Tierurztl. Mschr. 2008; 95: 116 -20.

9. Simoens R, Poles R, Lauwers H. Morphometric analysis of foramen magnum in Pekingese dogs. Am J Vet Res. 1994; 55: 33-9.

10. Nomina Anatomica Veterinaria. $5^{\text {th }}$ ed, prepared by the International Committe on Veterinary Gross Anatomical Nomenclature (I.C.V.G.A.N.) and authorized by the General assembly of the World Association of Veterinary Anatomists (W.A.V.A.), konxville,T.N (USA). Published by the Editorial Committee, Hannover, Columbia, Ghent and Sapporo. 2012; 11-9.

11. SAS. SAS statistical system Package-Jmp 8 User's Guide.2nd Cary, NC, SAS Institute Inc. USA. 2009, ISBN 978-1-60764-301-2. 
12. Sarma K, Nashiruddullah K, Islam S. Anatomy of the skull of a leopard cat (Felis bengalensis). Indian J. anim sci, 2001; 71 (11): 1011-3.

13. .Künzel, W, Breit S, Oppel M. Morphometric investigations of breed-specific features in feline skulls and considerations on their functional implications. Anat Histol Embryol, 2003; 32 (4): 218-23.

14. Monfared AL. Anatomy of the Persian Cat's Skull and its Clinical Value During Regional Anesthesia. Global Veterinaria. 201310 (5): 551-5.

15. Böhmer C, Böhmer E. Shape Variation in the Craniomandibular System and Prevalence of Dental Problems in Domestic Rabbits: A Case Study in Evolutionary Veterinary Science. Vet. Sci, 2017; 4, 5.

16. Nameer PO, Nasser PO, Ipe MO, Ommar PA. Anatomy of Jungle cat skull (Felis chaus, Schreber). Zoos' Print J, 2003; 18 (2): 1011-8.

17. Farag FM, Daghash SM, Mohamed EF, Hussein MM, Hagrass SM. Anatomical studies on the skull of the domestic rabbit (Oryctolagus cuniculus) with special reference to the hyoid apparatus. J. Vet. Anat, 2012; 5 (2): 49-70.

18. Nickel R, Schummer A, Seiferle E. Anatomy of the domestic animals. Vol . 1986, Verlag Paul Parey, Berlin and Hamburg.

19. Brewer NR. Historical Special Topic Overview on Rabbit Comparative Biology. J Am Assoc Lab Anim. 2006; 45 (1): 8-24.

20. Salih KM. Gross Anatomical And Morophmetrical Studies To The Skull Bones Of The Local Rabbit (Oryctohguscuniculus). Bas j vet Res. 2013; 12 (2), 267-77

21. King AM, Cranfield F, Hall J, Sullivan M. Anatomy and ultrasonographic appearance of the tympanic bulla and associated structures in the rabbit. Vet J. 2007; 173, 512-21.

22. Popesko P, Rajtova V, Horak J. 1992 A colour atlas of the anatomy of small laboratory animals, Vol.1, Rabbit and guinea pig. Wolfe Publishing, Bratislava.

23. Monfared AL. Applied Anatomy of the Rabbit's Skull and its Clinical Application During Regional Anesthesia. Global Veterinaria, 2013; 10 (6): 653-7.

24. Getty R. Sisson and Crossman: Carnivore Osteology. Skull. In the anatomy of the domestic animals. 1975, $5^{\text {th }}$ Ed. W.B. Saunders Company.

25. Miller ME. Guide to the dissection of the dog, 2004, fourth edition W.B. Saunders company.

26. Salih KM. Morphological and morph metric study of the mandible in the local Rabbits (Oryctolagus Cunicuius). Iraqi J. Vet. Sci. 2016; 40(1): 25-9.

27. Barone R, Pavaux C, Blin PC, Cuq P. 1973, Atlas of Rabbit Anatomy (Masson et Cie, Paris), $11-50$.

28. Little CJ, Lane JG. The surgical anatomy of the feline bulla tympanica. J Small Anim Pract, 1986; 27, 371-8.

29. Casteleyn C, Cornillie P, Hermens A, Van, LD, Hoorebeke LV, Broeck W, Simoens P. Topography of the rabbit paranasal sinuses as a prerequisite to model human sinusitis. Rhinology. 2010; 48 : $300-4$.

30. Varga M. Textbook of the rabbit medicine. 2014, Second edition. Butterworth Heinemann Elsevier inc.

31. Kara CO. Animal Models of Sinusitis: Relevance to Human Disease. Curr Allergy Asthma Rep. 2004; 4:496-9.

32. Pereira ME, Macri NP, Creasy DM. Evaluation of the Rabbit Nasal Cavity in Inhalation Studies and a Comparison with Other Common Laboratory Species and Man. Toxicol Pathol. 2011; 39: 893900.

33. Özkadif S, Eken E. Three-dimensional reconstruction of multidetector computed tomography images of paranasal sinuses of New Zealand rabbit. Turk J Vet Anim Sci. 2013; 37: 675-81.

34. Ozcan KM, Akdogan O, Kopara S, Ozcan I, Gurgen SG, Ozogul C, Selcuk A, Deren T, Dere H. Comparison of Histopathological and CT Findings in Experimental Rabbit Sinusitis. Indian J Otolaryngol Head Neck Surg. 201; 63: 56-9.

35 . Hadad S. Some anatomical studies on the development of the nasal cavity and its related structures in the white New Zeeland. PhD thesis. 2015.

36. Ragab SA, Abouelela YS, Daghash SM, Khattab MA, Tahon RR. Comparative morpho-logical and histochemical characteristics of the nasal cavity and paranasal sinuses of adult rabbits and domestic cats in Egypt. Inter J Vet Sci. 2018; 7 (2): 97-105. 